\title{
Thermal Performance Analysis of the Double- Sided Linear Switched Reluctance Motor
}

\author{
J. Garcia-Amoros, R. Bargalló-Perpiñà, P. Andrada, B. Blanqué
}

\begin{abstract}
This paper presents a study about the thermal performance of the double-sided flat Linear Switched Reluctance Motor (LSRM) according to the number of phases $(m)$ and the pole stroke (PS). The analysis is performed by means of the Finite Element Method (FEM) for electromagnetic computations and a lumped parameter for thermal model (LPT) both linked to an optimization algorithm based on the Response Surface Methodology (RSM) in order to reduce the computing time. The results show the LSRM behavior for achieving an optimal design from the point of view of the thermo-mechanical performance for a given insulation class and a duty cycle operating conditions.
\end{abstract}

Index Terms--Linear Switched Reluctance Motor, Finite element, Lumped parameter thermal model, Response Surface Methodology.

\section{NOMENCLATURE}

$b_{p} \quad$ Primary pole width $(m)$

$c_{p} \quad$ Primary slot width $(m)$

$T_{p}$ Primary pole pitch $(m)$

$l_{p} \quad$ Primary pole length $(m)$

$b_{s}$ Secondary pole width $(\mathrm{m})$

$c_{s} \quad$ Secondary slot width $(\mathrm{m})$

$T_{s}$ Secondary pole pitch $(m)$

$N_{s}$ Number of passive poles per side (Secondary)

$l_{s}$ Secondary pole length $(\mathrm{m})$

$h_{y} \quad$ Primary yoke height $(m)$

$L_{W}$ Stack length $(m)$

$g \quad$ Air gap length $(m)$

$P S$ Pole Stroke $(m)$

$S$ Distance between aligned-unaligned positions $(\mathrm{m})$

$m$ Number of phases

$x$ Translator position $(m)$

$w_{r}$ Dielectric width $(m)$

$J \quad$ Flat-topped current density peak $\left(A / m^{2}\right)$

\section{INTRODUCTION}

$\mathrm{L}$ INEAR Switched Reluctance Motors (LSRMs) are being recently object of study [1] [2] [3]. Their simplicity and robustness make them an attractive alternative to linear permanent magnet motors due to their low expected manufacturing costs and a good faulttolerance capability, although the power/weight ratio $(\mathrm{W} / \mathrm{kg})$ is significantly lower. LSRMs can be classified as transverse flux or longitudinal flux. In transverse flux, the

Jordi Garcia Amorós is with Electrical and Electronic Engineering Department at University Rovira i Virgili, Av. Països Catalans 26, 43007 Tarragona, Spain. (e-mail: jordi.garcia-amoros@urv.cat).

Ramon Bargalló Perpiñà is with Electrical Engineering Department Polytechnic University of Catalonia. EUETIB, C/Urgell, 187, 08036 Barcelona, Spain (e-mail: ramon.bargallo@upc.edu)

Pere Andrada and Balduí Blanqué are with Electrical Engineering Department. Polytechnic University of Catalonia. EPSEVG, Vulanova i la Geltrú 08800, Spain (e-mail:pere.andrada@upc.edu, blanque@ee.upc.edu) plane of movement and the magnetic flux plane are perpendicular. In the longitudinal case, these planes are parallel. The purpose of this work is to analyze a set of longitudinal LSRM configurations in regard to their propulsion force for a given operating conditions i.e. the maximum temperature rise (insulation class) and the IEC duty cycle. The number of phases $(m)$ and the pole stroke $(P S)$ define the set of LSRM configurations under analysis.

This analysis involves the combination of two different methodologies (FEM-LPT) for solving the magneticthermal field problem. In general coupled field problems are classified into weak or strong coupling, in weakcoupled problems the effects can be separated and solved by means a cascade algorithm [4]. The absence of permanent magnets in LSRM eases to handle the magnetothermal field as a weak-coupled field problem, and then the magneto-thermal phenomena is described from magnetic Poisson's equation (1) and Fourier (2) as: [5]

$$
\begin{gathered}
\nabla^{2} A=-\mu \cdot J \\
\nabla^{2} T-\frac{\gamma \cdot c}{k} \cdot \frac{\partial T}{\partial t}=-\frac{q}{k}
\end{gathered}
$$

Where in (1) it is assumed a slow magnetic variation (disregarding iron losses), and in (2) $\gamma$ is the mass density, $c$ the specific heat, $k$ the thermal conductivity, and the thermal source $q$ is only provided by the Joule losses.

In this study, the solution is obtained considering the magnetic and thermal fields (1-2) uncoupled in order to process the large amount of LSRM configurations studied in a reasonable computing time. This simplification leads to parallelize the resolution algorithm and to speed up the solution of each LSRM, though the results obtained should be considered as an approach to the real performance. Despite this fact, the results are coherent and give useful guidelines for the LSRM-design process.

\section{GEOMETRICAL AND THERMAL DESCRIPTION}

The longitudinal-flux LSRMs can be flat or tubular. The conventional double-sided flat LSRM is made by mirroring a single-sided longitudinal-flux flat LSRM whose result is two primary structures, one on each side and a secondary iron-connected poles. The modified double-sided LSRM differs from the conventional double-sided flat LSRM structure, in the secondary, which is comprised of rectangular poles without connecting iron yokes. The analysis is performed on the longitudinal-flux flat modified double-sided structure, LSRM hereinafter.

\section{A. Geometrical model}

The input geometrical variables, which characterize the LSRM, are the number of phases $(m)$ and the pole stroke 
$(P S)$. The FEM computations are made for each pair $(m, P S)$ which define a LSRM structure denoted as $\operatorname{LSRM}(m, P S)$. The electromagnetic propulsion force is computed in 20 evenly positions between the pole misalignment (taken as reference position i.e. $x=0)$ and the pole alignment $(x=S)$, and then it is averaged (3), where $S$ is given by $S=m \cdot P S / 2$.

$$
F_{X}(m, P S, J)=\frac{1}{S} \int_{0}^{S} F_{x}(m, P S, J, x) \cdot d x
$$

The range of study cases covered are $m \in\{2 \div 5\}$ phases $P S \in\{3 \div 10\} \mathrm{mm} J \in\{0.5 \div 20\} \mathrm{A} / \mathrm{mm}^{2}, x \in\{0 \div \mathrm{S}\} \mathrm{mm}$.

The parameters, which define the magnetic circuit dimensions, are: $b_{p}, l_{p}, b_{s} l_{s}$ and $h_{y}$ (see Fig. 1). These parameters are normalized to the stator pole pitch $T_{p}$ resulting: $\alpha_{p}=b_{p} / T_{p}, \beta_{p}=l_{p} / T_{p}, \alpha_{s}=b_{s} / T_{p}, \quad \beta_{s}=l_{s} / T_{p}, \delta_{y}=h_{y} / T_{p}$. The air-gap $(g)$ and the stack width $L_{W}$ are held constant. The stator length $L$ can be expressed as:

$$
L=(m-1) \cdot\left[(2 \cdot m-1)+\alpha_{p}\right] \cdot P S
$$

LSRM's geometry is determined from these geometrical proportions $\left\{\alpha_{p}, \alpha_{s}, \beta_{p}, \beta_{s}, \delta_{y}\right\}$ [6], and by means the equations (4- 6).

$$
\left.\begin{array}{c}
N_{p}=2 \cdot m \\
N_{s}=2 \cdot(m-1)
\end{array}\right\}
$$

The pole stroke $P S$ is defined as the distance covered by the secondary (generally the movable part or translator) from an aligned position to the next aligned position when two consecutive phases are excited. The $P S$ parameter is directly related with the LSRM size as it is shown in (4). Figure 1 depicts two LSRM configurations i.e. $\operatorname{LSRM}(2,3)$ and $\operatorname{LSRM}(3,3)$.

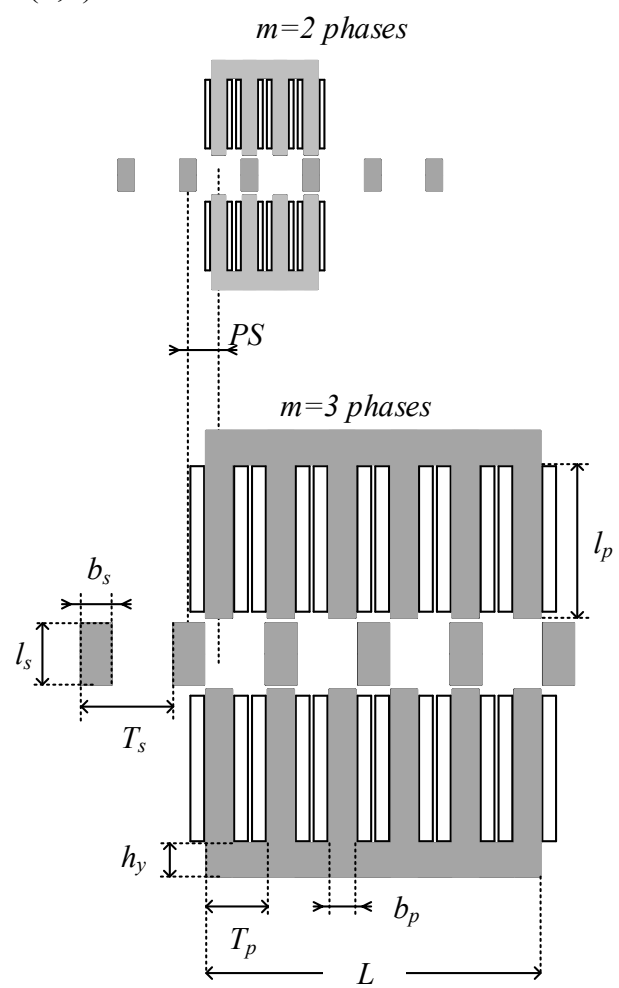

Fig. 1. LSRM main dimensions and LSRM $(m, P S)$ examples for $m=2$ and $m=3$ at constant $P S$.

\section{B. Thermal description}

Thermal analysis is carried out by means of a lumped parameters thermal model (LPT). In general the lumped models accuracy depends on the level of refinement of the network and on the knowledge of the heat transfer coefficients. In this case the thermal network elements (thermal resistances and capacitances) are parameterized according to the input variables $(m, P S)$ and its determination is based on [7]. For parameterizing and modelling the thermal network four main modules have been defined: 1) the outer poles (see Fig. 2a), placed these at the ends of the both primaries, 4 in total, 2) the inner poles (see Fig. 2b), placed between the outer poles, $4 \cdot(m-1)$ in total, 3) the primary iron and 4) the secondary iron.

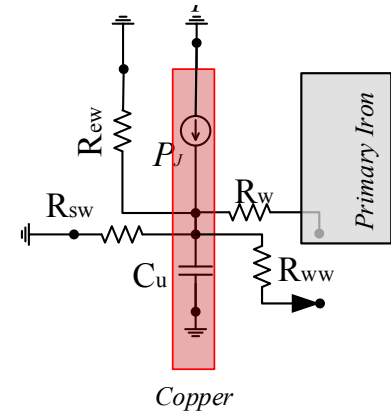

(a)

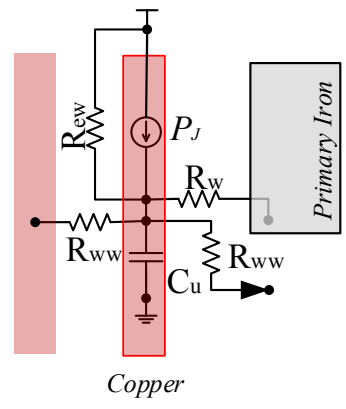

(b)
Fig. 2. Primary poles thermal model.

An example of thermal model network assembled using these modules for $\operatorname{LSRM}(2,3)$ is shown in figure 3 . The heat transfer coefficients were firstly estimated taking into account previous studies for rotating machines [8], and after, they were calibrated by thermal test over an LSRM $(4,4)$ prototype [7]. Their values are collected in the appendix (see table III).

Where $V_{p}(m, P S), V_{s}(m, P S)$ are the volume of the primary and secondary iron respectively and $V_{C u}(m, P S)$ is the copper volume, given by:

$$
\begin{aligned}
& V_{p}(m, P S)=\left[4 \cdot m \cdot \alpha_{p} \cdot \beta_{p}+2 \cdot \delta_{y} \cdot\left(2 \cdot m+\alpha_{p}-\right.\right. \\
& 1)] \cdot L_{W} \cdot(m-1)^{2} \cdot P S^{2} \\
& V_{s}(m, P S)=6 \cdot(m-1)^{3} \cdot P S^{2} \cdot \alpha_{s} \cdot \beta_{s} \cdot L_{W} \\
& V_{C u}(m, P S)=\left(1-\alpha_{p}\right) \cdot \beta_{p} \cdot T_{p}(m, P S)^{2}\left[\frac{\pi}{2} \cdot\left(1+\alpha_{p}\right) \cdot\right. \\
& \left.T_{p}(m, P S)+\beta_{p} \cdot L_{W}\right]
\end{aligned}
$$

The thermal losses considered are the Joule losses, which for a flat-topped current waveform are:

$$
P_{J}(m, P S, J)=\sigma \cdot V_{C u}(m, P S) \cdot\left(\frac{J(T)}{\sqrt{m}}\right)^{2}
$$

Where $\sigma$ is the electrical resistivity. 


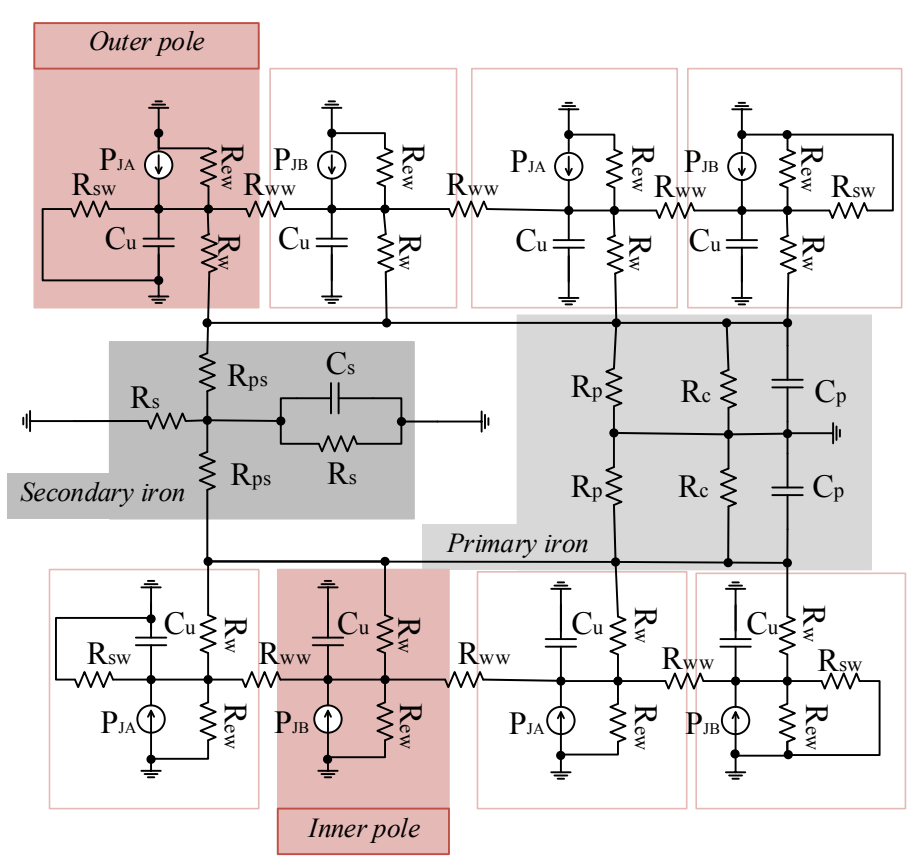

Fig. 3. Thermal equivalent circuit for the set of $m=2$ phases $\operatorname{LSRM}(2, P S)$.

The output of the LPT is the time-varying temperature of the $\operatorname{LSRM}(m, P S)$ configuration, averaged over the $n$ nodes of the thermal network (11).

$$
T_{a v g}(m, P S, J, t)=\frac{1}{n(m, p s)} \sum_{i=1}^{n(m, P S)} T_{i}(m, P S, J, t)
$$

The simulation time is 50000 seconds for all the cases, enough time to reach the rate temperature $T_{\max }$, and therefore $T_{\max }(m, P S, J)=T_{a v g}(t=50000 \mathrm{~s})$. From $(11)$, it is adjusted an exponential law (12) for each pair $(m, P S)$ from which the thermal time constant $K_{T}(m, P S)$ is obtained.

$$
T_{A V G}(m, P S, J, t)=T_{\text {max }}(m, P S, J) \cdot\left(1-e^{\frac{-t}{K_{T}(m, P S)}}\right)
$$

\section{RESPONSE SURFACE METHOdOLOGY}

The Response Surface Methodology (RSM) was first introduced by Box and Wilson [9] in 1951. RSM is efficacious when the process has no analytical expression to describe it or when the analytical expression is too complex and when there are some indeterminate factors not modeled. RSM creates an empirical model that relates the process response to well-known input parameters. Its application to electromagnetic problems started in the 90's [10] and other applications are founded on Jabbar [11] and Jolly [12] in the last decade.

The purpose is to achieve a set of design variables $\gamma$ in which the response $\eta$ reach a maximum or a minimum within an experimental region $\mathcal{R}$, which is defined by practical limitations like geometry, mechanical restrictions or saturation. The $k$-independent design variables are normalized to equally bounded factors $x_{1} ; x_{2} ; \ldots, x_{k}$ and these need to be capable of an exact measurement. In order to determine the response $\hat{y}$, the regression method of least squares is applied for multiple order polynomials, fitting the sure values $y$ ( $n$ design samples computed by FE-analysis). To minimize the computing time it is desired to keep $n$ as small as possible, which is dependent on the polynomial order and the number of factors $k$. The Design of
Experiments (DoE) is a tool used for determining the optimal test points for RSM.

RSM cannot substitute measurements and additional FE computations in the experimental region around the optimized response, but reduce them to a feasible number.

\section{A. Procedure}

Every process is characterized by a true response such as the propulsion force for a linear motor, which can be measured and hence underlies a measurement error $\varepsilon_{\mathrm{m}}$. It is self-explanatory that there are no prototypes available for every design sample $\operatorname{LSRM}(m, P S)$ to verify the FEM computations. For this reason a single computation result itself is assumed to be an adequate image of a real machine and defined as the true response $\eta$. However the evaluation of the FE-analysis is not always trivial and underlies an error $\varepsilon_{\text {eva. }}$. Considering this, the so-called sure value or mean response $y$ is described as:

$$
y=\eta+\varepsilon_{e v a}=f\left(x_{1}, x_{2}, \ldots . x_{i}\right)+\varepsilon_{e v a}
$$

In which $y$ is the measured response (i.e. average Force $F_{x}$, Temperature Rise $T_{\max }$ and other) and $x_{1}, x_{2}, \ldots . x_{i}$ are the input variables (in our case are: $m, P S$ and $J$ ) The evaluation of the error is random and assumed to have zero mean value and thereby $y$ is conditioned to be an adequate representation of the true response $\eta$. For relating the response to the input variables, the approximation function $f$ (13) needs to be attained. This is accomplished by means of a low-degree polynomial represented by a matrix of arguments $X$ and a matrix of coefficients $\beta(14)$.

$$
y=X \cdot \beta+\varepsilon_{\text {eva }}
$$

As an example, for the second-degree model $(d=2)$ we can write:

$$
y=\beta_{0}+\sum \beta_{i} \cdot x_{i}+\sum \sum \beta_{i j} \cdot x_{i} \cdot x_{j}
$$


In general the number of terms and coefficients of a $k$ variables and $d$-degree polynomials can be determined as:

$$
c=\left(\begin{array}{c}
k+d \\
d
\end{array}\right)=\frac{(k+d) !}{k ! \cdot d !}
$$

The design samples are represented by a matrix $\mathbf{D}=$ $\left[\mathbf{D}_{1}, \mathbf{D}_{2}, \ldots . \mathbf{D}_{\mathbf{n}}\right]$ containing the different geometries, for which the response $y$ has been computed previously by the FE-analysis. This leads us to the following over-determined linear system of equations:

$$
Y=\left(\begin{array}{c}
y_{1} \\
y_{2} \\
\cdots \\
y_{n}
\end{array}\right)=\left(\begin{array}{c}
X_{1} \\
X_{2} \\
\cdots \\
X_{n}
\end{array}\right) \cdot \beta+\epsilon=Z \cdot \beta+\epsilon
$$

The coefficient vector $\beta$ is determined under the approach of linear least squares [13]. Its so-called ordinary least-squares estimator $\beta$ and henceforth the predicted response $\hat{y}$ for every single point in the experimental region $\mathcal{R}$ can be obtained by:

$$
\left.\begin{array}{c}
\hat{\beta}=\left(Z \cdot Z^{T}\right)^{-1} \cdot Z^{T} \cdot Y \\
\hat{y}=\hat{\beta} \cdot X
\end{array}\right\}
$$

In general, it is desired to have a low number of samples, but this has to exceed the number of coefficients $c$ of the underlying multi-order tri-variate polynomials. Consequently, for a second-order polynomial, 10 coefficients are required, which can be provided by different RSM designs: Full Factorial Design, Box Behnken Desing or Central Composite Design. References [4]-[9] describe the details of the application of each one of these cited methodologies in order to minimize the number of samples and to achieve maximum fitting of the experimental results to the selected polynomial adjust.

\section{OPTIMAL OF DESIGN}

In our study case the optimization problem can be easily established, since it consists on maximize the average propulsion force $\left(F_{X}\right)$ as function of the number of phases $(m)$, pole stroke $(P S)$ and current density $(J)$ :

$$
\begin{gathered}
\max \left(F_{X}\right) \\
F_{X}=f(m, P S, J)
\end{gathered}
$$

Subject to the following geometrical conditions:

$$
\left.\begin{array}{c}
m=[2,3,4,5] \\
3 m m \leq P S \leq 10 \mathrm{~mm} \\
0.5 \mathrm{~A} / \mathrm{mm}^{2} \leq J \leq 20 \mathrm{~A} / \mathrm{mm}^{2}
\end{array}\right\}
$$

And the restriction of maximum temperature rise:

$$
T_{M A X}(m, P S, J) \leq T_{\text {LIMIT }}
$$

To solve this problem, the first step is to obtain a polynomial representation of each of the above parameters. As an example, figure 4 a shows the force (3) as function of $P S$ and $J$ for $m=4$ phases. In general, for all of the $\operatorname{LSRM}(m, P S)$ designs, the maximum force is achieved at $J=20 \mathrm{~A} / \mathrm{mm}^{2}$ and $P S=10 \mathrm{~mm}$, which are the limit values.
Figure $4 \mathrm{~b}$ shows the temperature rise (12).

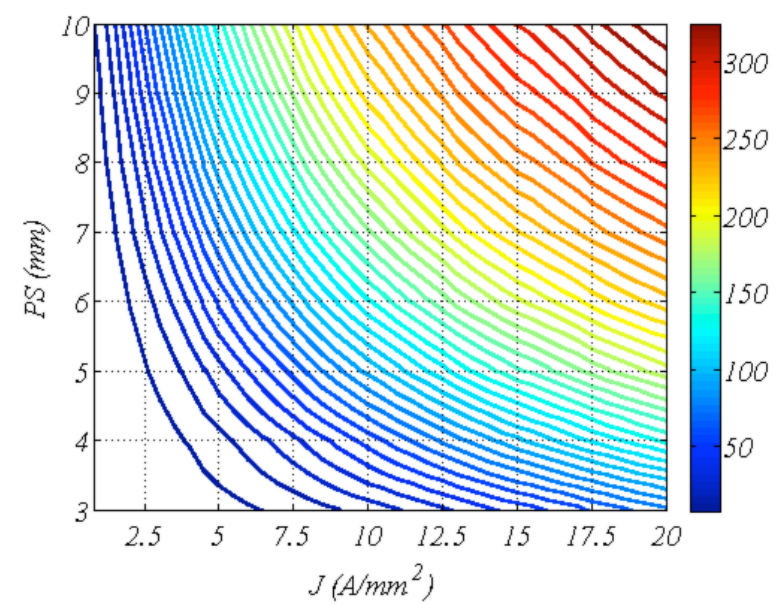

(a)

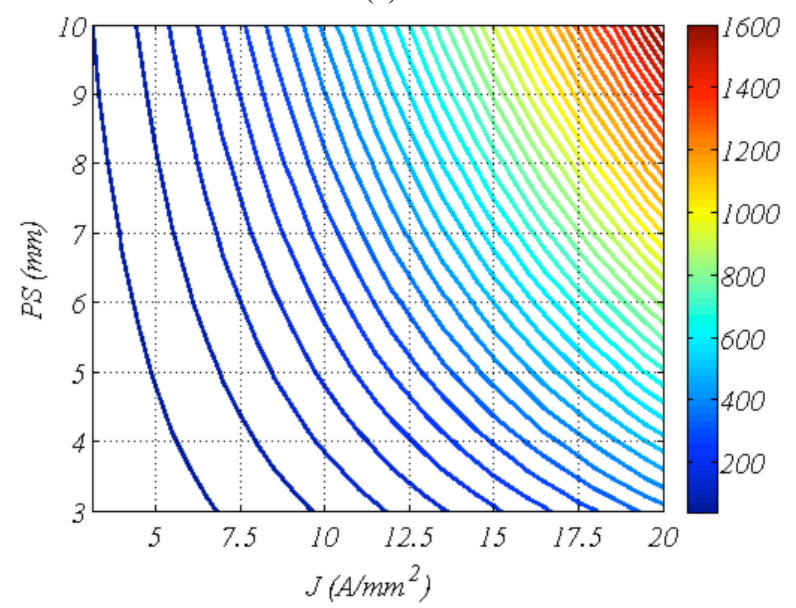

(b)

Fig. 4. a) Average force $F_{X}(4, P S, J)$ in Newton (N). b) Steadystate temperature rise $T_{M A X}(4, P S, J)$ in Celsius-degrees $\left({ }^{\circ} \mathrm{C}\right)$.

It is also considered a polynomial fit on the thermal time constant $\left(K_{T}\right)$ as function of $P S$ and $m$. In this case a linear approximation is obtained. Figure 5 shows the obtained experimental results and the linear fit using $m$ as parameter.

Figure 6 summarizes the optimization algorithm in which for each number of phases and fixing a maximum temperature rise $\left(T_{\text {limit }}\right)$, it is calculated the optimal values of pole stroke $(P S)$ and current density $(J)$ that maximize the propulsion force $\left(F_{X}\right)$.

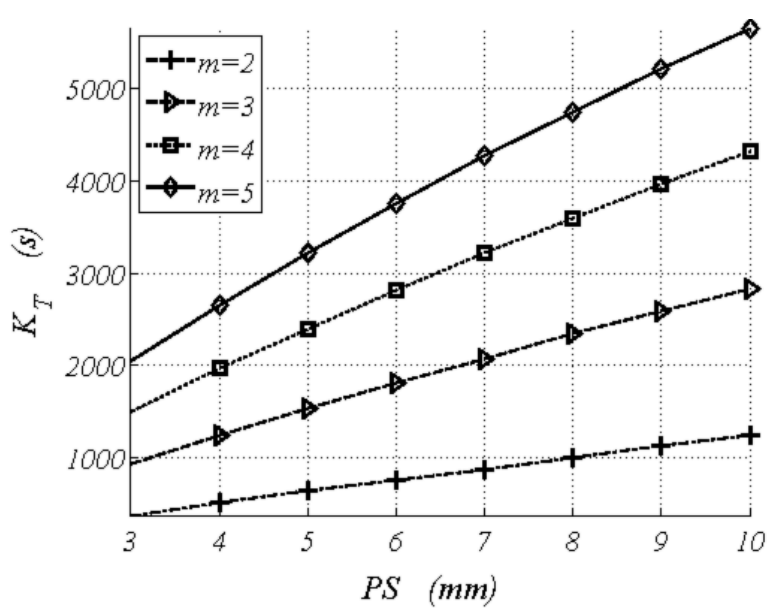

Fig. 5. Thermal time constant $K_{T}$ as a function of $P S$ and $m$. 
If there are no temperature restrictions, the optimization algorithm (see fig. 6) determines the limit values for $P S$ and $J$ (i.e. $P S=10 \mathrm{~mm}$ and $J=20 \mathrm{~A} / \mathrm{mm}^{2}$ ), since these values give the maximum force. From these values the maximum temperature reached is calculated, being this $T_{\text {real }}$. Table I summarizes these results for a continuous Duty Cycle $(D C)$ $\mathrm{S} 1$, and considering the cases of no limit temperature-rise (unrestricted temperature) and the insulation systems Bclass and F-class, whose temperature-rise limits are $80^{\circ} \mathrm{C}$ and $100^{\circ} \mathrm{C}$ respectively. When the maximum temperaturerise is taken as a restriction, the current density and the force are dramatically reduced.

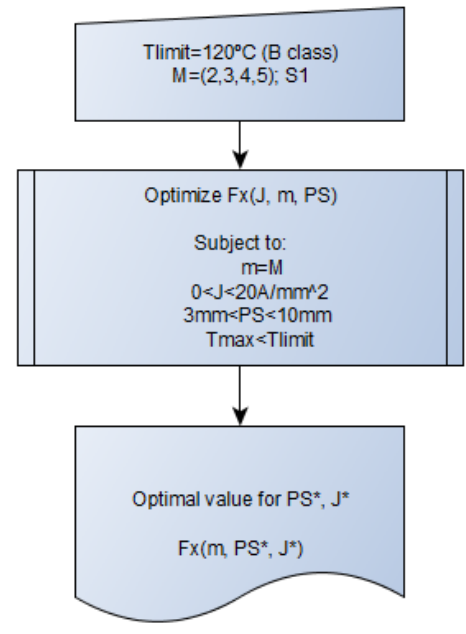

Fig. 6. Algorithm for S1 service optimization.

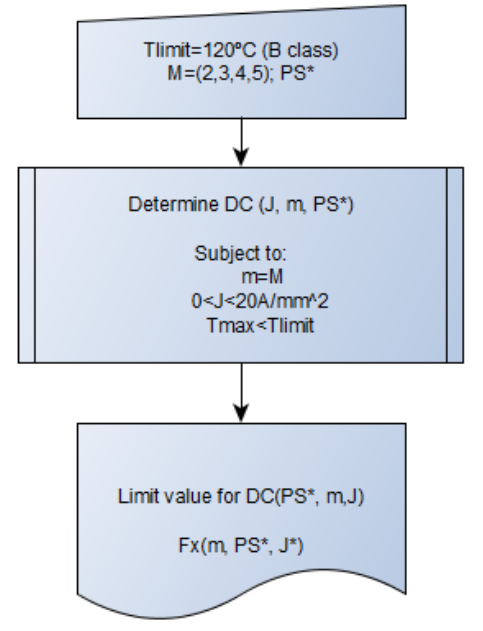

Fig. 7. Algorithm for S3 service optimization.

TABLE I

OPTIMAL DESIGN FOR A S1 CLASS SERVICE.

\begin{tabular}{|c|c|c|c|c|c|}
\hline$\Delta T_{\text {limit }}\left({ }^{\circ} \mathrm{C}\right)$ & $\begin{array}{c}m \\
(\mathrm{ph} .)\end{array}$ & $\begin{array}{c}P S \\
(\mathrm{~mm})\end{array}$ & $\begin{array}{c}J \\
\left(\mathrm{~A} / \mathrm{mm}^{2}\right)\end{array}$ & $\begin{array}{c}F_{X} \\
(\mathrm{~N})\end{array}$ & $\begin{array}{c}\Delta T_{\text {real }} \\
(\underline{\mathrm{o}} \mathrm{C})\end{array}$ \\
\hline NO LIMIT & 2 & 10 & 20 & 47.9 & 781 \\
\hline B-CLASS 80 & 2 & 10 & 6.39 & 6 & 80 \\
\hline F-CLASS 100 & 2 & 10 & 7.15 & 7.52 & 100 \\
\hline NO LIMIT & 3 & 10 & 20 & 212 & 1293 \\
\hline B-CLASS 80 & 3 & 10 & 4.97 & 52.3 & 80 \\
\hline F-CLASS 100 & 3 & 10 & 5.56 & 61.8 & 100 \\
\hline NO LIMIT & 4 & 10 & 20 & 332 & 1641 \\
\hline B-CLASS 80 & 4 & 10 & 4.42 & 117 & 80 \\
\hline F-CLASS 100 & 4 & 10 & 4.94 & 132 & 100 \\
\hline NO LIMIT & 5 & 10 & 20 & 421 & 1903 \\
\hline B-CLASS 80 & 5 & 10 & 4.1 & 174 & 80 \\
\hline F-CLASS 100 & 5 & 10 & 4.58 & 194 & 100 \\
\hline
\end{tabular}

Other important parameter that should be considered for optimal design is the type of service (continuous $D C=100 \%$ or intermittent duty $D C<100 \%$ ). In general, LSRMs have a non-continuous service; according to IEC-60034-1 the duty cycle operating conditions S3 is taken as study case. In this case the optimization process starts from the maximum current density $J_{\max }$ and then it is determined the maximum force and $D C$ without exceeding the limit insulation class temperature (B-class: $\Delta T \leq 80^{\circ} C$ ). Figure 7 shows this optimization algorithm and table II summarizes the obtained results.

TABLE II

OPTIMAL DESIGN FOR $\$ 3$ SERVICE $(P S=10)$. B-CLASS.

\begin{tabular}{|c|c|c|c|c|c|c|c|c|}
\hline & \multicolumn{2}{|c|}{$m=2$} & \multicolumn{2}{|c|}{$m=3$} & \multicolumn{2}{c|}{$m=4$} & \multicolumn{2}{c|}{$m=5$} \\
\hline$J_{M A X}$ & $\begin{array}{c}F \\
(N)\end{array}$ & $\begin{array}{c}D C \\
(\%)\end{array}$ & $\begin{array}{c}F_{X} \\
(N)\end{array}$ & $\begin{array}{c}D C \\
(\%)\end{array}$ & $\begin{array}{c}F_{X} \\
(N)\end{array}$ & $\begin{array}{c}D C \\
(\%)\end{array}$ & $\begin{array}{c}F_{X} \\
(N)\end{array}$ & $\begin{array}{c}D C \\
(\%)\end{array}$ \\
\hline 20 & 48 & 3.8 & 212 & 5.1 & 332 & 3 & 421 & 6,7 \\
\hline 18 & 41 & 4.7 & 200 & 6.3 & 317 & 7.5 & 400 & 8.3 \\
\hline 16 & 34 & 6.1 & 185 & 8.1 & 301 & 9.6 & 383 & 10.6 \\
\hline 14 & 27 & 8.1 & 169 & 10.8 & 282 & 12.6 & 363 & 13.9 \\
\hline 12 & 21 & 11 & 149 & 15 & 260 & 17.5 & 339 & 19.3 \\
\hline 10 & 14 & 18 & 126 & 22.7 & 235 & 26.1 & 312 & 28.5 \\
\hline 8 & 9 & 35 & 99 & 39 & 204 & 43.7 & 281 & 47.2 \\
\hline $\mathbf{6}$ & $\mathbf{6}$ & $\mathbf{1 0 0}$ & 69 & 92.7 & 161 & 94.9 & 241 & 92.6 \\
\hline $\mathbf{4 . 9}$ & - & - & $\mathbf{5 2 . 3}$ & $\mathbf{1 0 0}$ & - & - & - & - \\
\hline $\mathbf{4 . 4}$ & - & - & - & - & $\mathbf{1 1 7}$ & $\mathbf{1 0 0}$ & - & - \\
\hline $\mathbf{4 . 1}$ & - & - & - & - & - & - & $\mathbf{1 7 4}$ & $\mathbf{1 0 0}$ \\
\hline
\end{tabular}

Figure 8 summarizes the optimal average propulsion force restricted by the insulation class temperature and as function of the duty cycle. The time-cycle was established in 1 hour (3600s).

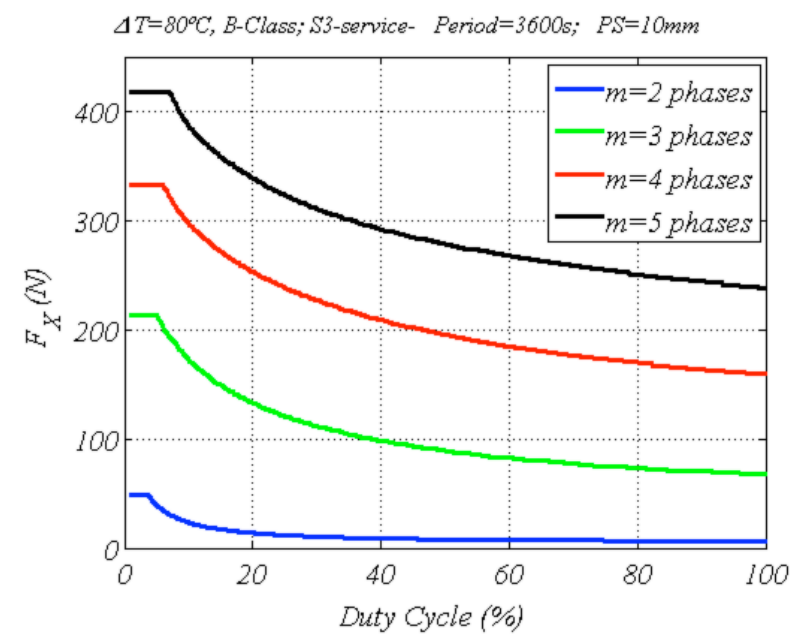

Fig. 8. Optimal $F_{X}$ vs. Duty Cycle. B-class insulation.

Figure 9 depicts the current density which maximize the propulsion force (see Fig. 8) as function of the number of phases and the $D C(\%)$ for a temperature rise of $\Delta T=80^{\circ} C$ (B-class insulation). As it is expected the current density increases as the $D C$ decreases. The five-phase configuration can operate with higher current densities due to its higher size and better refrigeration surface, except for DC $>70 \%$ in which the 2-phase configuration exhibits a slightly better behavior. 


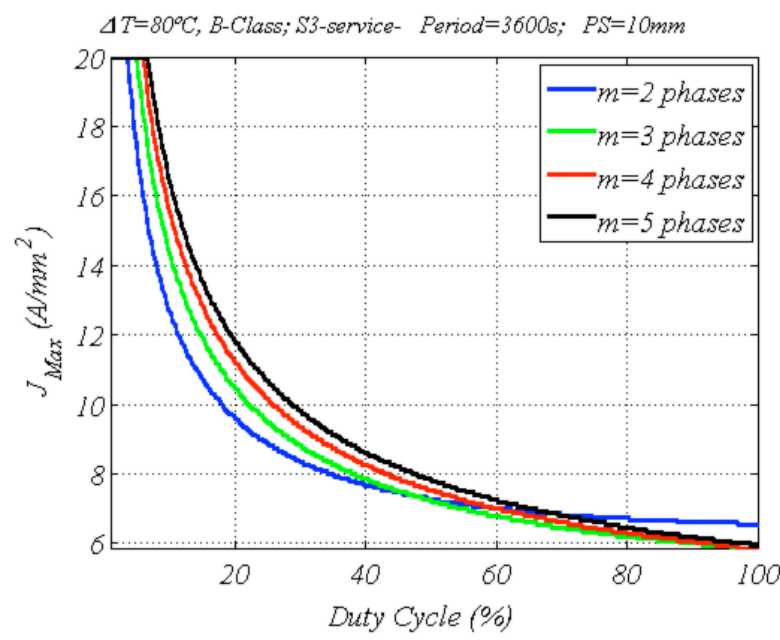

Fig. 9. Optimal Current density vs. Duty Cycle.

\section{CONCLUSIONS}

In this paper a novel model-analysis of LSRM is presented, in which the optimal propulsion force for a range of LSRM configurations is obtained by means of the combination of three techniques: Finite Element Analysis (FEA), Response Surface Methodology (RSM) and Lumped Parameter Thermal network (LPT). This modeling methodology (FEA-RSM-LPT) allows obtaining different optimization algorithms with consuming time in the FEcalculations. For each configuration of $\operatorname{LSRM}(m, P S, J)$ the thermal analysis is performed, obtaining the maximum temperature rise and the thermal time constant for continuous operating conditions.

From FEA-RSM and LPT results, an optimization algorithm is defined from which the propulsion force is optimized subject to the restrictions of the insulation class temperature-rise and the duty cycle operating conditions. As it is expected, the maximum average force occurs for maximum $P S$ and $m$. Further research will be released in upcoming papers taking into consideration other performance indices like force ripple factor and force per unit iron/copper mass, and considering also the weakcoupled magneto-thermal field.

\section{APPENDIX}

TABLE III. - THERMAL PARAMETERS

\begin{tabular}{|l|}
\hline Process \\
\hline Convection: end winding to air. \\
$h_{e w}=6.9 \mathrm{~W} /\left(\mathrm{m}^{2} \cdot K\right)$ \\
$R_{e w}=\left(h_{e w} \cdot \pi \cdot \beta_{p} \cdot T_{p}(m, P S)^{2}\right)^{-1}$ \\
\hline Conduction: through 1 layer of dielectric. \\
$k_{w}=0.04633 \mathrm{~W} /(\mathrm{m} \cdot \mathrm{K})$ \\
$R_{w}=w_{r} \cdot\left(2 \cdot \beta_{p} \cdot T_{p}(\mathrm{~m}, P S) \cdot L_{W}\right)^{-1}$ \\
\hline Convection: primary iron to air. \\
$h_{p}=1.753 \mathrm{~W} /\left(\mathrm{m}^{2} \cdot \mathrm{K}\right)$ \\
$R_{p}=\left(h_{p} \cdot L(m, P S) \cdot L_{W}\right)^{-1}$ \\
\hline Radiation: Primary to secondary. \\
$h_{p s}=7 \mathrm{~W} /\left(\mathrm{m}^{2} \cdot K\right)$ \\
$R_{p s}=\left(h_{p} \cdot L(m, P S) \cdot L_{W}\right)^{-1}$ \\
\hline Conduction: through 2 layer of dielectric. \\
$R_{w w}=2 \cdot R_{w}$ \\
\hline Convection: primary's external-surface to air. \\
$h_{c}=5.7 \mathrm{~W} /\left(\mathrm{m}^{2} \cdot K\right)$ \\
$R_{c}=\left(20 \cdot h_{c} \cdot L(m, P S) \cdot L_{W}\right)^{-1}$ \\
\hline
\end{tabular}

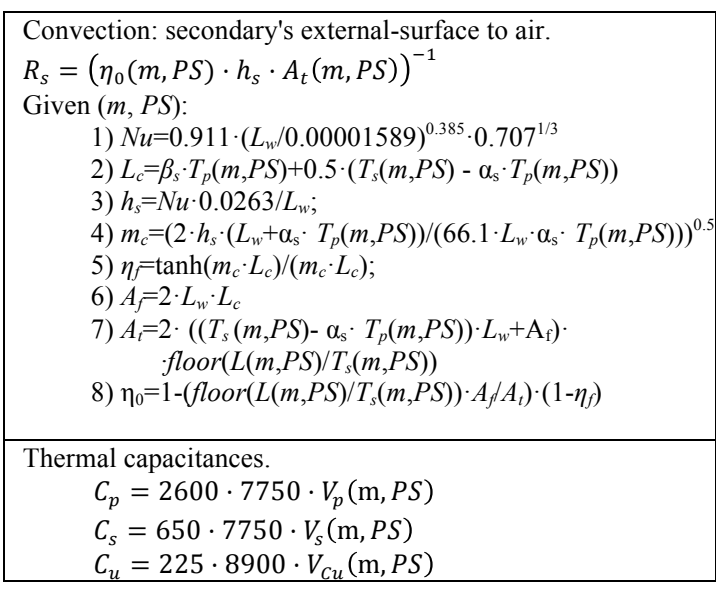

\section{REFERENCES}

[1] Wenlong Li; Chau, K.T.; Chunhua Liu; Chun Qiu, "Design and Analysis of a Flux-Controllable Linear Variable Reluctance Machine", IEEE Transactions on Applied Superconductivity, vol.24, no.3, pp.1-4, June 2014.

[2] Chen, H.; Sun, C.; Wang, Q., "Analysis of Flux-Linkage Characteristics of Switched Reluctance Linear Generator", IEEE Transactions on Applied Superconductivity, vol.24, no.3, pp.1-5, June 2014.

[3] Garcia-Amorós, J.; Blanqué Molina, B.; Andrada, P., "Modelling and simulation of a linear switched reluctance force actuator", IET Electric Power Applications, vol.7, no.5, pp.350-359, May 2013.

[4] Hameyer, K.; Driesen, J.; De Gersem, H.; Belmans, R., "The classification of coupled field problems", IEEE Transactions on Magnetics, vol.35, no.3, pp.1618-1621, May 1999.

[5] Eustache, P.; Meunier, G.; Coulomb, J. L., "Finite Element Toolbox for Generic Coupling (magnetic, thermal, etc)", IEEE Transactions on Magnetics, vol.32, no.3, pp.1461-1464, May 1996.

[6] Amoros, J. G.; Andrada, P., "Sensitivity Analysis of Geometrical Parameters on a Double-Sided Linear Switched Reluctance Motor", IEEE Transactions on Industrial Electronics, vol.57, no.1, pp.311319, January. 2010.

[7] Amoros, J.G.; Andrada, P.; Blanque, B., "An analytical approach to the thermal design of a double-sided linear switched reluctance motor", XIX International Conference on Electrical Machines (ICEM), 2010 , vol., no., pp.1-4, 6-8 Sept. Rome.

[8] Boglietti A.; Cavagnino A.; Staton, D., "Determination of Critical Parameters in Electrical Machine Thermal Models", IEEE Transactions on Industry Applications, vol.44, no.4, pp.1150-1159, July-aug. 2008.

[9] G. E. P. Box and K. B. Wilson, "On the experimental attainment of optimum conditions," Journal of the Royal Statistical Society. Series B (Methodological), vol. 13, no. 1, pp. 1-45, 1951.

[10] Jolly, "Design optimization of permanent magnet motors using response surface methodology and genetic algorithms", Master's thesis, National University of Singapore, 2005.

[11] R. Rong, D. Lowther, Z. Malik, H. S., J. Nelder, and R. Spence, "Applying response surface methodology in the design and optimization of electromagnetic devices," Magnetics, IEEE Transactions on, vol. 33, no. 2, pp. 1916-1919, 1997.

[12] M. Jabbar, L. Q., and L. Jolly, "Application of response surface methodology (rsm) in design optimization of permanent magnet synchronous motors," in TENCON 2004 IEEE Region 10 Conference, vol. C, 2004, pp. 500-503 Vol. 3

[13] A. I. Khuri and S. Mukhopadhyay, "Advanced review: Response surface methodology," WIREs Computational Statistics, vol. 2, pp. $128-149,2010$. 
[14] G. E. P. Box and D. W. Behnken, "Some new three level designs for the study of quantitative variables," Technometrics, vol. 2, no. 4, pp. $455-475,1960$.

[15] D. C. Meeker, Finite Element Method Magnetics, Version 4.2 (15Nov2013 Build), http://www.femm.info

\section{BIOGRAPHIES}

Jordi Garcia Amorós (M’09) was born in Barcelona (Spain) in 1970. $\mathrm{He}$ received the B.Sc., M.Sc. and $\mathrm{PhD}$. degrees in Industrial Engineering from Polytechnic University of Catalonia (UPC Barcelona), in 1992, 2004 and 2010 respectively. He is currently associate professor in electrical engineering at the School of Engineering of the University Rovira i Virgili (ETSE), Tarragona (Spain). His research interests and teaching activities are in the field of modeling and design of electrical machines.

Ramon Bargalló Perpiñà was born in Badalona, Catalonia, Spain, on May, 10 of 1962. He received the B.Sc., MSc, and PhD degrees in Industrial Engineering from the Polytechnic University of Catalonia (UPC), in 1985, 1995, and 2001 respectively. He is currently Professor in Electrical Engineering Department at EUETIB of UPC. Also he has about 50 papers on International Conferences and Journals. His employment experience includes assessment of some companies about the improvement of design of electrical machines and transformers and the use of FE methodology. His research interests are in the field of design of electrical machines.

Pere Andrada (M'91) was born in Barcelona (Spain) in 1957. He received the M.Sc. and the PhD. degrees in Industrial Engineering from the Universitat Politècnica de Catalunya (UPC), Barcelona, Spain, in 1980 and 1990 respectively. In 1980 he joined the Department of Electrical Engineering, Universitat Politècnica de Catalunya UPC, where he is currently Associate Professor in the Escola Politècnica Superior d'Enginyeria de Vilanova i la Geltrú (EPSEVG). His teaching activities and research interests include design, modeling and control of electrical machines and drives.

Balduí Blanqué was born in Reus (Tarragona, Spain) in 1970. He received the B.S. degree in Telecommunications, the M.S. degree in Telecommunications, and the Ph.D. degree from the Universitat Politècnica de Catalunya (UPC), in Barcelona, Spain, in 1996, 1999, and 2007, respectively. Since 1996, he has been with the Department of Electrical Engineering, Universitat Politècnica de Catalunya (UPC), where he is currently an Assistant Professor in the Escola Politècnica Superior d'Enginyeria de Vilanova i la Geltrú (EPSEVG) 